\title{
THE EVALUATION OF A TOOL FOR DISSEMINATION OF BIOTECHNOLOGY AND MOLECULAR BIOLOGY CONCEPTS IN FORMAL EDUCATION
}

\author{
F.M. Escanhoela, A.C.R. Guerra, F.M. Chiari, M.R.G. Oliveira, L.M.Beltramini \\ Centro de Biotecnologia Molecular Estrutural (CBME/CEPID/FAPESP), \\ Instituto de Física de São Carlos, Universidade de São Paulo, São Paulo, Brazil \\ E-mail: felipemoron@if.sc.usp.br
}

Since 2003, the CBME Scientific Dissemination Coordination has developed a project related to the production and distribution of a scientific dissemination newspaper, called CBME InFORMAÇÃO, directed to high-school students and teachers. It is a quarterly publication and shows the concepts and advances of studies in molecular biology and biotechnology. In order to evaluate the newspaper, a research was accomplished in 2005. It involved 177 students from six high schools of São Carlos and region. In addition, opinions of five science teachers that worked with the newspaper in their classrooms, as well as eight Biology undergraduates were collected. The teachers received some questionnaires that had to be answered by them and their students after a specify activity with the periodical - basically, the activities consisted of three stages: individual reading of the newspaper; formulation of questions by the teacher and, finally, group discussion on the chosen theme. The research confirmed the importance of the use of the periodical as a tool in the formation of critical readers of facts related to the biotechnology and molecular biology, what should contribute with the citizenship development in the students. Moreover, it provided a possibility to reorganize the periodical. 